\title{
Drop Metastasis in Glioblastoma Multiforme
}

Sir,

Glioblastoma multiforme (GBM) is a common primary malignancy of the central nervous system. Development of extracranial metastasis in GBM is a rarity. ${ }^{[1,2]}$ Although spinal dissemination from intracranial GBM via cerebrospinal fluid has been clinically validated in many reports, a much higher incidence was reported in an autopsy series. ${ }^{[3]}$ Here, we report a case of GBM presenting with a drop-like metastasis to the spine on disease progression.

A 43-year-old male presented with the complaints of headache and giddiness of 5 days' duration. Imaging of the brain revealed a right temporal lobe mass lesion with significant perilesional edema. He underwent craniotomy and near-total excision of the tumor. Histopathology was reported as WHO Grade IV glioma (GBM, not otherwise specified). The patient completed postoperative concurrent chemoradiation (60 Gy in 30 fractions with concurrent temozolomide) and adjuvant chemotherapy with temozolomide for 6 months, which he completed by July 2019.

In November 2019, the patient presented with the complaints of severe low back ache and headache. A magnetic resonance imaging (MRI) brain with whole spine was done.

Coronal T2-weighted MRI brain showed a recurrent mass lesion of size $6.1 \mathrm{~cm} \times 8.7 \mathrm{~cm} \times 7.7 \mathrm{~cm}$ in the right ganglionic region and the right temporal lobe, invading the base of the skull and infratemporal fossa [Figure 1a]. Axial T2-weighted MRI image at the level of the middle cranial fossa showed a large recurrent mass in the right temporal lobe associated with the surrounding edema [Figure 1b].
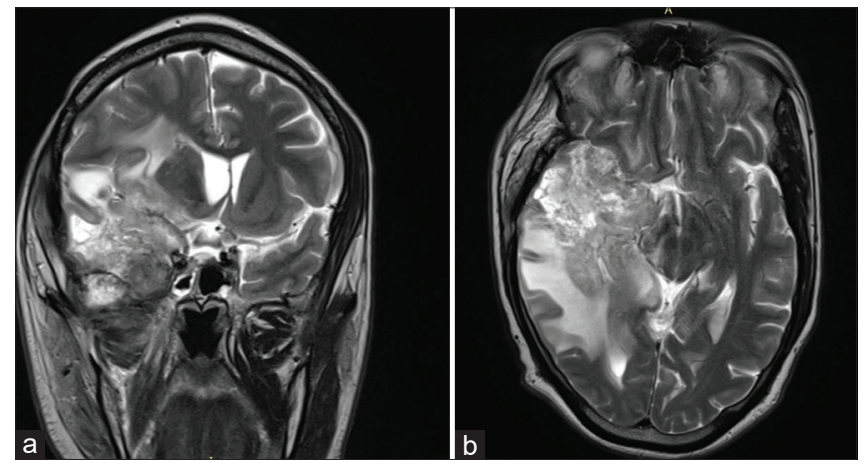

Figure 1: (a) Coronal T2-weighted magnetic resonance imaging showing recurrent mass lesion of size $6.1 \mathrm{~cm} \times 8.7 \mathrm{~cm} \times 7.7 \mathrm{~cm}$ in the right ganglionic region and the right temporal lobe invading the base of the skull and infratemporal fossa. (b) Axial T2-weighted magnetic resonance imaging at the level of middle cranial fossa showing a large recurrent mass in the right temporal lobe associated with marked perilesional edema and mass effect
MRI spine revealed multiple lesions suggestive of metastasis involving the thoracic, lumbar, and sacral vertebrae. Sagittal T2-weighted MRI of the spine showed altered signal intensity and collapse of the T7 vertebral body, suggestive of metastasis with the associated soft tissue, causing mild cord compression [Figure 2].

In view of the extensive metastatic lesions, the patient was evaluated with a whole-body ${ }^{18}$ fluoro-2-deoxyglucosepositron emission tomography-computed tomography (FDG-PET-CT). Axial PET-CT image showed a metabolically active recurrent brain lesion in the right temporal lobe and a metabolically active vertebral body lesion suggestive of metastasis and a FDG-avid right Level II lymph node [Figure 3a-c].

PET-CT was suggestive of progression of the cranial lesion with multiple spinal metastases. FDG-avid right Level II lymph node did not reveal any significant pathology on biopsy. The patient and his relatives were reluctant to take biopsy from the spinal lesion.

As the patient had severe pain in the region of spinal metastasis, palliative radiation therapy was given to the region of spinal metastasis and pain management was done in the form of morphine and analgesics and antiepileptics. After explaining the poor prognosis of the disease to the patient and his family, the patient was started on palliative chemotherapy with single-agent bevacizumab intravenously at the dose of $10 \mathrm{mg} / \mathrm{kg}$ for every 2 weeks. After three cycles of bevacizumab, he had a dramatic improvement in pain especially while on movements, and he was continued on treatment. After completing five cycles of bevacizumab, the patient had clinical and radiological progression with features of cavernous sinus involvement in the form of

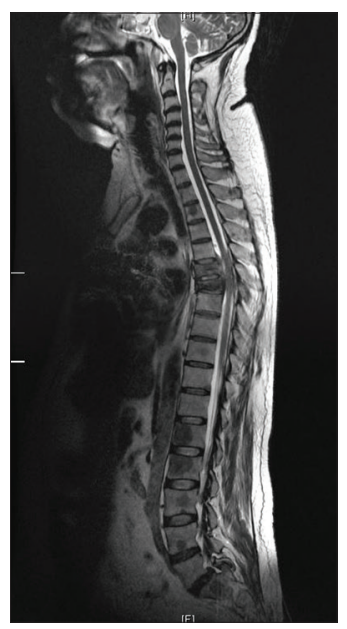

Figure 2: Sagittal T2-weighted magnetic resonance imaging of the spine showing multiple vertebral metastases and collapse of T6-T7 vertebral bodies with the associated soft-tissue component 


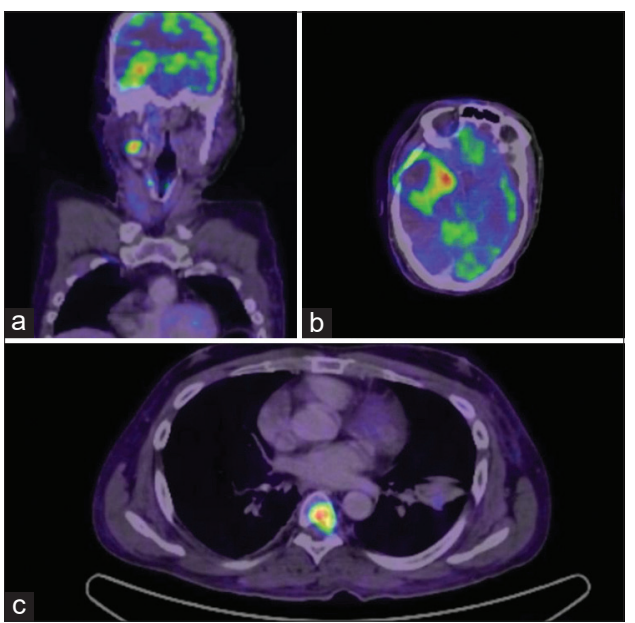

Figure 3: (a-c) Axial positron emission tomography-computed tomography image showing a metabolically active recurrent brain lesion in the right temporal lobe and a metabolically active vertebral body lesion suggestive of metastasis and a fluoro-2-deoxyglucose-avid right Level II lymph node

ophthalmoplegia, proptosis, conjunctival congestion, and Horner's syndrome and was continued on best palliative and supportive care.

The incidence of drop metastasis to spinal cord in glioblastoma is estimated at around $2 \%$ at relapse, but symptomatic spinal metastasis at progression is very rare.

Spinal metastases occur as a result of cellular spread in the subarachnoidal space or hematogenous dissemination. They disseminate via the cerebrospinal fluid onto the spine owing to the effect of gravity. ${ }^{[4]}$ Drop metastases usually occur in the dorsal aspect of the lower thoracic, upper lumbar, and lumbosacral spine.

Patients with such drop metastasis tend to do poorly and usually progress despite second-line treatment with a median duration of survival between 2 and 4 months. ${ }^{[5]}$

\section{Declaration of patient consent}

The authors certify that they have obtained all appropriate patient consent forms. In the form the patient(s) has/have given his/her/their consent for his/her/their images and other clinical information to be reported in the journal. The patients understand that their names and initials will not be published and due efforts will be made to conceal their identity, but anonymity cannot be guaranteed.

Financial support and sponsorship

Nil.

\section{Conflicts of interest}

There are no conflicts of interest.

Mintu Mathew, TM Anoop, P Rona Joseph

Department of Medical Oncology, Regional Cancer Centre, Thiruvananthapuram, Kerala, India

Address for correspondence: Dr. TM Anoop,

Department of Medical Oncology, Regional Cancer Centre, Thiruvananthapuram, Kerala, India. E-mail:dranooptm@yahoo.co.in

Submitted: 29-Apr-2020 Accepted in Revised Form: 01-Aug-2020

Published: 29-Aug-2020

\section{References}

1. Shah A, Redhu R, Nadkarni T, Goel A. Supratentorial glioblastoma multiforme with spinal metastases. J Craniovertebr Junction Spine 2010;1:126-9.

2. Goodwin CR, Liang L, Abu-Bonsrah N, Hdeib A, Elder BD, Kosztowski $\mathrm{T}$, et al. Extraneural glioblastoma multiforme vertebral metastasis. World Neurosurg 2016;89:578-82000.

3. Ng WH, Yeo TT, Kaye AH. Spinal and extracranial metastatic dissemination of malignant glioma. J Clin Neurosci 2005; 12:379-82.

4. Pande SB, Pavithran K. Drop metastases to the spinal cord from infratentorial glioblastoma multiforme in post-temozolomide era. J Cancer Res Ther 2015;11:1039.

5. Scoccianti S, Detti B, Meattini I, Iannalfi A, Sardaro A, Leonulli BG, et al. Symptomatic leptomeningeal and intramedullary metastases from intracranial glioblastoma multiforme: A case report. Tumori 2008;94:877-81.

This is an open access journal, and articles are distributed under the terms of the Creative Commons Attribution-NonCommercial-ShareAlike 4.0 License, which allows others to remix, tweak, and build upon the work non-commercially, as long as appropriate credit is given and the new creations are licensed under the identical terms.

\begin{tabular}{|l|l|}
\hline \multicolumn{2}{|c|}{ Access this article online } \\
\hline Quick Response Code: & Website: \\
& www.ijmpo.org \\
\cline { 2 - 2 } & DOI: \\
\hline
\end{tabular}

How to cite this article: Mathew M, Anoop TM, Joseph PR. Drop metastasis in glioblastoma multiforme. Indian J Med Paediatr Oncol 2020;41:625-6. 